\title{
Association of Serum Ferritin level with the Development of CKD in Diabetic Patients
}

${ }^{1}$ Rafiq Ahmad Siddiqui, ${ }^{2}$ Tahira Naseem, ${ }^{2}$ Farhana Mukhtar, ${ }^{3}$ Ambreen Farrukh, ${ }^{4}$ Saadia Liaqat

${ }^{1}$ Department of Biochemistry, Services Institute of Medical Sciences, Lahore

${ }^{2}$ Department of Biochemistry \& Chemical Pathology, Shaikh Zayed Medical Complex, Lahore

${ }^{3}$ Department of Chemical Pathology, Abwa Medical College, Faisalabad

${ }^{4}$ Gynae Hospital Union Council 37, New Karol, Lahore

\begin{abstract}
Introduction: Ferritin is the storage form of iron in our body. Different studies have shown that serum ferritin level is raised in patients suffering from type 2 diabetes mellitus. In DM the glycation of protein is facilitated by iron which creates oxidative stress, inflammation and damage to kidney giving rise to chronic renal disease. Aims \& Objectives: Comparison of serum ferritin level of diabetic patients with CKD and without CKD and its correlation with random plasma glucose, urinary albumin creatinine ratio and e-GFR. Determination of serum ferritin level as an assessment parameter for CKD progression in type 2 diabetics. Place and duration of study: Department of Biochemistry \& Chemical Pathology, SZPGMI, Lahore, from January to December 2017. Material \& Methods: The study comprised of 100 type 2 diabetic patients divided into two groups. Group I comprised of 50 diabetics without CKD and group II comprised of 50 diabetics with CKD. Random plasma glucose, blood urea, serum creatinine, serum ferritin, urinary albumin and urinary creatinine were estimated for all the participants. e-GFR $(\mathrm{ml} / \mathrm{min})$ and urinary albumin to creatinine ratio (ACR) $(\mathrm{mg} / \mathrm{g})$ were calculated. The comparison of all parameters was done between both groups. The comparison of serum ferritin level was done and its correlation with other parameters was observed in both the groups. Results: The mean serum ferritin level $(\mathrm{ng} / \mathrm{ml})$ was significantly higher in group II $(580.4 \pm 539.6)$ as compared to group I $(105.4 \pm 55.6)$ (p-value $<0.001)$. Conclusion: Serum ferritin level in this study was found to be significantly elevated in type 2 DM patients with CKD when compared with type 2 diabetics without CKD. Since iron creates oxidative stress, raised ferritin levels in type 2 diabetics may be an indication of progression to CKD. Hence in diabetic patients the estimation of serum ferritin level may be performed routinely to assess the development of CKD at an earlier stage.
\end{abstract}

Key words: Ferritin, Diabetes Mellitus, Chronic Kidney Disease (CKD).

\section{INTRODUCTION}

$\mathrm{D}$ abetes Mellitus (DM) is considered to be a very common endocrine disease. ${ }^{1}$ It is a metabolic syndrome having hyperglycemia and is a major problem for health. A complex interaction of genetics and environmental factors is the cause of diabetes mellitus. ${ }^{2}$ Epidemiological data showed that there were 285 million diabetics in the world in 2010 and it is estimated that this number might increase up to about 440 million in the year $2030 .^{3}$ In the developing countries, the prevalence of DM is increasing rapidly. Seven percent of the population is affected by type $2 \mathrm{DM} .{ }^{4}$ The number of diabetics has been increasing due to the sedentary lifestyle, obesity, rapid growth in population, urbanization and longer survival of diabetic patients. ${ }^{5}$
Nephropathy is one of the most important and common complications of DM. It is characterized by high blood pressure, albuminuria and a gradual loss of kidney function giving rise to end stage renal disease (ESRD). Almost $40 \%$ of type 2 diabetics develop renal complication. ${ }^{6}$ It is, therefore, considered as the leading cause of CKD worldwide. In addition, oxidative stress and inflammation are the risk factors which by interacting with each other increase the occurrence and progression of kidney injury. ${ }^{7}$ The gradual loss of renal function occurring in a time span of months or years is seen in CKD. National Kidney Foundation has defined CKD as either GFR $<60 \mathrm{ml} / \mathrm{min} / 1.73 \mathrm{~m}^{2}$ for $\geq 3$ months or kidney damage. Kidney damage is diagnosed by the pathological abnormalities or the markers of its damage which include abnormalities in imaging studies, urine tests or blood tests. ${ }^{8}$ 
The biomarkers used in routine practice to detect kidney disease include serum creatinine, creatinine clearance (eGFR) and microalbuminuria.

In microalbuminuria an abnormally higher amount of albumin is excreted in urine falling in the range of $30-299 \mathrm{mg} / \mathrm{g}$ creatinine. To detect increased excretion of urinary protein, urinary Albumin-tocreatinine ratio (ACR) is measured..$^{9}$ Although albuminuria is considered as the gold standard biomarker of glomerular injury at present, some other proteins have also been suggested as useful markers of kidney damage. ${ }^{10}$

It is of utmost importance to screen type 2 diabetics regarding the development of diabetic nephropathy so that the associated morbidity and mortality can be prevented and managed well in time. ${ }^{11}$

Ferritin is the stored form of iron, found in liver, spleen, heart, bone marrow, kidney and pancreas. The measurement of serum ferritin specifically represents the level of iron in the body. Ferritin is also an acute phase protein, elevated during inflammatory conditions and this increase is independent of the iron status of the body. Hence the high level of ferritin reflects the state of inflammation and iron overload giving rise to oxidative stress. ${ }^{12}$ In type $2 \mathrm{DM}$, serum ferritin levels are found to be higher and these have got positive correlation with FBS and HbAlc. ${ }^{13}$ In chronic hyperglycemic state the primary cause of hyperferritinemia might be due to abnormalities in ferritin metabolism as a result of glycation. The serum half-life of glycosylated ferritin is longer and there is an influence of glycemic control on serum ferritin concentration. The glycated form of ferritin releases free iron which causes oxidative damage to the tissues. ${ }^{14}$ In DM the glycation of protein is facilitated by iron which creates oxidative stress, inflammation and damage to kidney giving rise to chronic renal disease. In the renal biopsies of patients with CKD, iron is seen to be deposited in the lysosomes of proximal convoluted tubules of kidneys. ${ }^{15}$ Free radicals such as hydroperoxide have got powerful pro-oxidant properties. Membrane properties are changed and result in tissue damage including renal tubules (leading to CKD). ${ }^{16}$

Serum ferritin level has been reported to be significantly higher in type 2 diabetics as compared to pre-diabetics and similarly in pre-diabetics as compared to the healthy people. ${ }^{17}$ The level of serum ferritin rises as the duration of DM increases. ${ }^{18}$ Serum ferritin level can be used as a parameter of insulin resistance as well as of the control of glycemia. ${ }^{19}$

Routine monitoring of serum ferritin level in diabetic patients might be useful to assess the glycemic control and thus the development of complications like CKD. The objective of this study was to compare serum ferritin level in type 2 diabetic groups with $\mathrm{CKD}$ and without $\mathrm{CKD}$ and to correlate it with random plasma glucose, urinary albumin creatinine ratio and e-GFR in both the groups.

\section{MATERIAL AND METHODS}

\section{Study Setting:}

This study was performed in the Department of Biochemistry and Chemical pathology, Shaikh Zayed Hospital, Lahore in 2017 and the patients were selected from the Department of Medicine, Nephrology and Diabetic Clinic of the hospital. After approval from ethical review board, patients were selected for the study and written consent was taken from the participants. The study was done through non-probability convenience sampling and the lab values of study parameters were recorded on the designed proforma.

\section{Study Population:}

100 diabetic patients between 35 to 75 years of age, comprising of equal number of males and females, were included in the study according to the following distribution:

Group-I 50 Patients of type $2 \mathrm{DM}$ without CKD.

Group-II 50 Patients of type 2 DM with CKD (diagnosed for at least five years and having known CKD complication).

Following individuals were excluded from the study.

1. Individuals who recently donated blood or received blood transfusion.

2. Patients having bleeding disorders or hemoglobinopathies.

3. Patients of hemochromatosis, hemosiderosis or receiving iron supplements.

4. Individuals on steroids and antioxidant drugs.

5. Individuals with active infections, neoplasia and seriously ill patients.

6. Alcoholics and pregnant women.

Serum Ferritin, Random Plasma Glucose, Blood Urea, Serum Creatinine and Urinary Albumin and Creatinine (Spot) were performed on all the participants. Creatinine clearance (e-GFR) was calculated from serum creatinine by using $\mathrm{CG}$ (Cockcroft and Gault) formula.Urinary Albumin to Creatinine Ratio was calculated in $\mathrm{mg} / \mathrm{g}$.

All the tests except ferritin were performed by using fully automated chemistry analyzer Beckman Coulter AU 480. Serum Ferritin assay was performed by using Immulite 1000 auto analyzer. The tests were performed in the Biochemistry lab of Shaikh Zayed Hospital, Lahore. 


\section{Statistical analysis:}

SPSS 20.0 was used for data entry and analysis. Pvalue was generated by Kruskal Wallis $\mathrm{H}$ test, oneway ANOVA, Mann Whitney-U test and Pearson correlation test. P-value $\leq 0.05$ is considered significant.

\section{RESULTS}

There was no marked difference of age between Group I and Group II (Table-1).

The mean plasma glucose $(\mathrm{mg} / \mathrm{dl})$, median blood urea and serum creatinine levels were significantly higher in group II as compared to group I (p-value $<0.001)$ (Table-1).

The mean serum ferritin level $(\mathrm{ng} / \mathrm{ml})$ in group II was higher significantly than that in group I (p-value $<0.001$ ) (Table-1) (Fig-1). The serum ferritin in males was generally higher as compared to females but statistically this difference was insignificant ( $p$ value 0.305) (Table-1) (Fig-I).

Regarding urinary parameters, group II had higher urine albumin as compared to group I ( $p$-value < $0.001)$ but there was no significant difference in median urine creatinine between the two groups ( $\mathrm{p}$ value 0.420 ) (Table-2). Median albumin creatinine ratio was higher significantly in group II compared with group I (p-value < 0.001) (Table-2). Median eGFR was higher significantly in group I compared with that in group II ( $\mathrm{p}$-value $<0.001)$ (Table-2).

\begin{tabular}{|c|c|c|c|}
\hline Parameters & $\begin{array}{c}\text { Group I } \\
\mathbf{n = 5 0} \mathbf{5 0}^{\boldsymbol{a}}\end{array}$ & $\begin{array}{c}\text { Group II } \\
\mathbf{n = 5 0}{ }^{\boldsymbol{a}}\end{array}$ & p-value \\
\hline Age (years) & $\begin{array}{c}52.0 \\
(41.8-58.5)\end{array}$ & $\begin{array}{c}50.5 \\
(45.0-59.3)\end{array}$ & $0.259^{b}$ \\
\hline $\begin{array}{c}\text { Random Plasma } \\
\text { Glucose } \\
(\mathrm{mg} / \mathrm{dl})\end{array}$ & $253.0 \pm 24.3$ & $316.7 \pm 58.9$ & $<0.001^{{ }^{*}}$ \\
\hline $\begin{array}{c}\text { Blood Urea } \\
(\mathrm{mg} / \mathrm{dl})\end{array}$ & $\begin{array}{c}26.6 \\
(22.6-31.4)\end{array}$ & $\begin{array}{c}197.3 \\
(108.3-234.8)\end{array}$ & $<0.001^{*^{c}}$ \\
\hline $\begin{array}{c}\text { Serum Creatinine } \\
(\mathrm{mg} / \mathrm{dl})\end{array}$ & $\begin{array}{c}0.90 \\
(0.80-1.0)\end{array}$ & $\begin{array}{c}3.7 \\
(2.8-4.4)\end{array}$ & $<0.001^{{ }^{*}}$ \\
\hline $\begin{array}{c}\text { Serum Ferritin } \\
(\mathrm{ng} / \mathrm{ml})\end{array}$ & $105.4 \pm 55.6$ & $580.4 \pm 539.6$ & $<0.001^{*}{ }^{*}$ \\
\hline
\end{tabular}

Table-1: Comparison of demographic characteristics and laboratory parameters between Group I and II

${ }^{a}$ For quantitative data values are given as mean \pm SD for normally distributed variables and median(IQR) for non normally distributed variables.

${ }^{b} p$-value is generated by Kruskal Wallis $\mathrm{H}$ test

${ }^{c} p$-value is generated by one way ANOVA

$* p$-value $\leq 0.05$ is considered statistically significant.

\begin{tabular}{|c|c|c|c|}
\hline Parameters & $\begin{array}{c}\text { Group I } \\
\mathbf{n = 5 0} \mathbf{5}^{\boldsymbol{a}}\end{array}$ & $\begin{array}{c}\text { Group II } \\
\mathbf{n}=\mathbf{5 0}^{\boldsymbol{a}}\end{array}$ & p-value \\
\hline $\begin{array}{c}\text { Urine Albumin } \\
(\mathrm{mg} / \mathrm{dl})\end{array}$ & $\begin{array}{c}1.0 \\
(1.0-2.0)\end{array}$ & $\begin{array}{c}121.1 \\
(80.7-173.1)\end{array}$ & $<0.001^{* b}$ \\
\hline $\begin{array}{c}\text { Urine Creatinine } \\
(\mathrm{mg} / \mathrm{dl})\end{array}$ & $\begin{array}{c}97.0 \\
(71.0-114.1)\end{array}$ & $\begin{array}{c}87.9 \\
(65.8-107.5)\end{array}$ & $0.420^{b}$ \\
\hline $\begin{array}{c}\text { Albumin } \\
\text { Creatinine Ratio } \\
(\mathrm{mg} / \mathrm{g})\end{array}$ & $\begin{array}{c}11.5 \\
(9.4-17.2)\end{array}$ & $\begin{array}{c}1487.9 \\
(812.1-2011.6)\end{array}$ & $<0.001^{* b}$ \\
\hline $\begin{array}{c}\mathrm{e}-\mathrm{GFR} \\
(\mathrm{ml} / \mathrm{min})\end{array}$ & $\begin{array}{c}71.9 \\
(63.4-85.7)\end{array}$ & $\begin{array}{c}18.9 \\
(15.2-29.8)\end{array}$ & $<0.001^{* b}$ \\
\hline
\end{tabular}

Table-2: Comparison of urinary parameters between group I and Group II

${ }^{a}$ Values are given as median(IQR) for non normally distributed variables.

${ }^{b} p$-value is generated by Mann Whitney-U test

${ }^{*} p$-value $\leq 0.05$ is considered statistically significant.

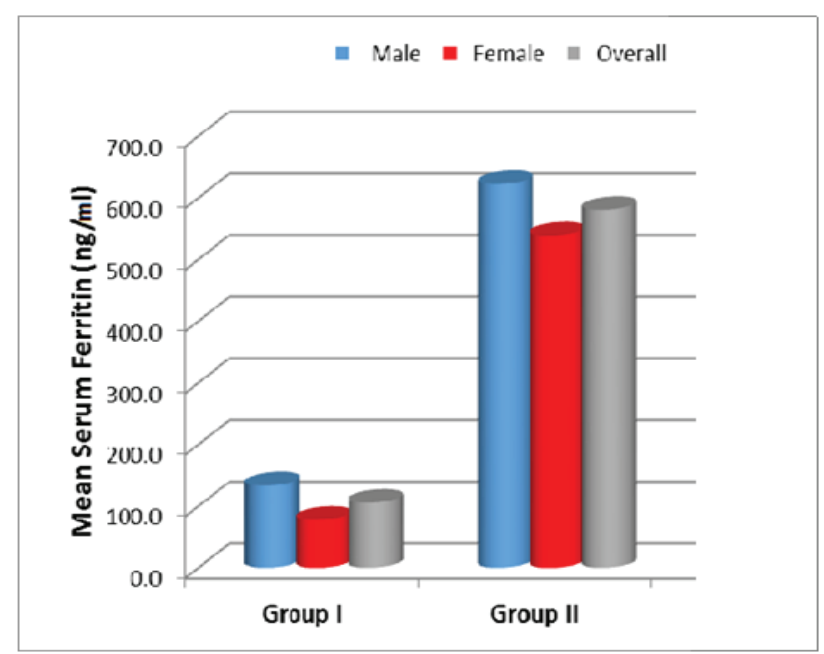

Fig-1: Comparison of Mean Serum Ferritin (ng/ml) between the two groups.

The correlation between serum ferritin and random plasma glucose was weak negative in group I $(\mathrm{r}=0.039, \mathrm{p}$-value 0.786$)$ whereas there was weak positive correlation in group II $(r=0.117$, $p$-value 0.418 ) and both are insignificant.

The correlation of serum ferritin levels with urinary albumin creatinine ratio was weak positive in group $\mathrm{I}(\mathrm{r}=0.071, \mathrm{p}$-value 0.626$)$ and II $(\mathrm{r}=0.107$, $\mathrm{p}$-value 0.461 ) but it was also insignificant.

The correlation between serum ferritin and e-GFR in group I was weak and positive $(\mathrm{r}=0.205$, $\mathrm{p}$-value $0.152)$ but for group II, it was negative $(r=-0.041$, $\mathrm{p}$-value 0.775 ). 


\section{DISCUSSION}

This study was performed on type 2 diabetics with and without CKD to determine if serum ferritin level can be used as a predictor to assess progression of CKD in type 2 diabetic patients. Both male and female subjects in the age group of 35-75 years were included. The difference of age between both the groups was not significant. The duration of DM in patients with CKD was at least five years. Similar criteria were observed in a previous study. ${ }^{16}$ The random plasma glucose level in group II (DM with CKD) was found to be significantly higher than that of group I (DM without CKD). It reveals that, usually, there is poor glycemic control in complicated cases of DM as observed in similar studies. ${ }^{15}$

The median blood urea and serum creatinine level in group II was significantly higher compared with that in group I. As described in other studies, renal impairment evidenced by elevated serum creatinine levels was common in chronic diabetics. ${ }^{20,21}$

The median urine albumin level was higher significantly in group II compared with that in group I. The difference of median urine creatinine between the two groups was not significant. Median urinary albumin creatinine ratio $(\mathrm{mg} / \mathrm{g})$ was higher significantly in group II compared with that in group I (p-value $<0.001)$. In a recent study it was described that in renal disorder the sensitive and early markers were microalbuminuria and urinary albumin creatinine ratio. ${ }^{22}$

The median e-GFR (calculated by CG formula) in group II was significantly lower than that found in group I. In a previous study Diabetic Kidney Disease (DKD), which was previously called diabetic nephropathy, has been defined as diabetes having impaired glomerular filtration rate $\left(<60 \mathrm{ml} / \mathrm{min} / 1.73 \mathrm{~m}^{2}\right)$, albuminuria (ratio of urine albumin to creatinine $\geq 30 \mathrm{mg} / \mathrm{g}$ ) or both and it has been described as the strongest sole predictor of mortality in patients of DM. ${ }^{23}$

The mean level of serum ferritin was found higher significantly in group II compared with that in group I. Serum ferritin level was somewhat higher in males as compared to that in females in both groups but the difference was statistically insignificant. Some other workers, in their study, observed similar results in which serum ferritin was raised in type 2 $\mathrm{DM}$ as long as glycemic control was not achieved and they also stated that this rise in ferritin might contribute to the pathogenesis of diabetes and in the progress of its complications. ${ }^{24,25}$

Several other workers also showed similar results in their studies. ${ }^{26}$ In a study increased serum ferritin levels were associated with poor glycemic control, insulin resistance and also with the complications of type-2 DM like neuropathy, retinopathy, nephropathy and hypertension. ${ }^{27}$ In some studies it was observed that there was an association between increased levels of serum ferritin and different risk factors of CKD including metabolic syndrome, hypertension, dyslipidemia, obesity and insulin resistance syndrome. ${ }^{28,29}$ In a recent study serum ferritin level was found to be elevated in patients of type $2 \mathrm{DM}$ with chronic kidney disease (CKD) which might be due to an inflammation or increased body iron stores. ${ }^{16}$

Hence the results of the current study are in accordance with those of the afore-mentioned studies. It was also observed in this study that with increasing duration of DM, the inverse correlation between serum ferritin and e-GFR (high ferritin level and low e-GFR) goes on developing and becomes established in cases of DM having CKD.

\section{CONCLUSION}

It may be concluded from this study that the serum ferritin level was markedly increased in type 2 diabetics with CKD as compared to that in nonCKD diabetics.

Serum ferritin was found to have positive correlation with blood urea and serum creatinine and a negative correlation with e-GFR (CG Formula) in diabetics with CKD. Serum ferritin was also found to have positive correlation with urinary albumin creatinine ratio in patients of DM with CKD.

These findings suggest that the regular monitoring and measurement of serum ferritin level might become a useful and non-invasive parameter for the early detection of renal involvement leading to CKD in type 2 diabetics.

\section{REFERENCES}

1. Senghor A, Bharathya N, Kumar JS, William E. Balasubramaniam. Serum ferritin, iron, TIBC, $\mathrm{Hb}$ in male patients with dysglycemia. Int $\mathrm{J}$ Biol Med Res. 2012; 3(2):1609-1.

2. American Diabetes Association. Diagnosis and classification of diabetes mellitus. Diabetes care. 2010 Jan 1; 33(Supplement 1):S62-9.

3. Shaw JE, Sicree RA, Zimmet PZ. Global estimates of the prevalence of diabetes for 2010 and 2030. Diabetes research and clinical practice. 2010 Jan 1; 87(1):4-14.

4. Pereira PF, Rita de Cássia GA, Araújo RM. Does breastfeeding influence the risk of 
developing diabetes mellitus in children? A review of current evidence. Jornal de pediatria. 2014 Jan 1; 90(1):7-15.

5. da Saúde. Diretrizes da Sociedade Brasileira de Diabetes. AC Farmac^eutica. 2013-2014.

6. Barbieri J, Fontela PC, Winkelmann ER, Zimmermann CE, Sandri YP, Mallet EK, Frizzo $\mathrm{MN}$. Anemia in patients with type 2 diabetes mellitus. Anemia. 2015.

7. Cachofeiro V, Goicochea M, De Vinuesa SG, Oubiña $\mathrm{P}$, Lahera $\mathrm{V}$, Luño J. Oxidative stress and inflammation, a link between chronic kidney disease and cardiovascular disease: New strategies to prevent cardiovascular risk in chronic kidney disease. Kidney International. 2008 Dec 1; 74:S4-9.

8. Myers GL, Miller WG, Coresh J, Fleming J, Greenberg N, Greene T, Hostetter T, Levey AS, Panteghini M, Welch M, Eckfeldt JH. Recommendations for improving serum creatinine measurement: a report from the Laboratory Working Group of the National Kidney Disease Education Program. Clinical chemistry. 2006 Jan 1; 52(1):5-18.

9. Toto RD. Microalbuminuria: definition, detection, and clinical significance. The journal of clinical hypertension. 2004 Nov; 6:2-7.

10. Currie G, McKay G, Delles C. Biomarkers in diabetic nephropathy: Present and future. World journal of diabetes. 2014 Dec 15; 5(6):763.

11. Devarajan P. Neutrophil gelatinase-associated lipocalin (NGAL): a new marker of kidney disease. Scandinavian journal of clinical and laboratory investigation. 2008 Jan 1; 68 (sup241):89-94

12. Muckenthaler M, Richter A, Gunkel N, Riedel D, Polycarpou-Schwarz M, Hentze S, Falkenhahn M, Stremmel W, Ansorge W, Hentze MW. Relationships and distinctions in iron-regulatory networks responding to interrelated signals. Blood. 2003 May 1; 101(9): 3690-8.

13. Thanna RC, Nigosker S. Level of Serum ferritin and Glycated hemoglobin (HbA1C) in type 2 diabetes mellitus. International Journal of Medical and Health Research. 2016.

14. Sharifi F, Nasab NM, Zadeh HJ. Elevated serum ferritin concentrations in prediabetic subjects. Diabetes and Vascular Disease Research. 2008 Mar; 5(1):15-8.

15. Kashinakunti SV, Hiremath K, Rangappa M, Kallaganada GS. Serum ferritin level in type 2 diabetes mellitus-A case control study. International Journal of Clinical Biochemistry and Research. 2016; 3(1):62-6.
16. Selvi VK, Fathima MW, Sivakumar N, Prabhu K. Estimation of serum ferritin level in type 2 diabetes mellitus with chronic kidney disease. J Chem Pharm Res. 2015; 7(10):246-249.

17. Kesav S, Ponnudhali D. Serum ferritin in prediabetes \& diabetes mellitus type 2 and its relationship with glycemic status. International Journal of Clinical Biochemistry and Research. 2017; 4(4):338-41.

18. Raj S, Rajan GV. Correlation between elevated serum ferritin and $\mathrm{HbAlc}$ in type 2 diabetes mellitus. Int J Res Med Sci. 2013 Jan; 1(1):12-5.

19. Rawat N, Mathur N, Harikrishnan R, Choudhary J, Rawat K, Mathur M. A study of correlation of serum ferritin with glycated haemoglobin in diabetes mellitus type 2 patients: a case control study. Asian Pac J Health Sci. 2016; 3(4):83-8.

20. Erejuwa OO, Sulaiman SA, Ab Wahab MS, Sirajudeen KN, Salleh MS, Gurtu S. Glibenclamide or metformin combined with honey improves glycemic control in streptozotocin-induced diabetic rats. International journal of biological sciences. 2011; 7(2):244.

21. Cao J, Li C, Zhang P, Cao X, Huang T, Bai Y, Chen K. Antidiabetic effect of burdock (Arctiumlappa L.) root ethanolic extract on streptozotocin-induced diabetic rats. African Journal of Biotechnology. 2012 May 8; 11(37): 9079-85.

22. Karar T, Alniwaider RA, Fattah MA, Al Tamimi W, Alanazi A, Qureshi S. Assessment of microalbuminuria and albumin creatinine ratio in patients with type 2 diabetes mellitus. Journal of natural science, biology, and medicine. 2015 Aug;6(Suppl 1):S89.

23. Reidy K, Kang HM, Hostetter T, Susztak K. Molecular mechanisms of diabetic kidney disease. The Journal of clinical investigation. 2014 Jun 2; 124(6):2333-40.

24. Borah M, Goswami RK. Evaluation of serum ferritin in in type II diabetes mellitus: a hospital based observational study from Dibrugarh, Assam, India. Int J Res Med Sc. 2016 Nov; 4(11):4916-21.

25. Arora P. Correlation between Serum Ferritin and Glycated Hemoglobin Level in Patients of Type 2 Diabetes Mellitus. Int J Cur Res Rev| Vol. 2017 Mar 1; 9(6):30.

26. Pramiladevi R, Boke U, Kora S. Serum ferritin levels in type II diabetes mellitus. Sch J App Med Sci. 2013; 1(5):472-5. 
27. SmotraS, Kudyar RP. Relationship between Serum Ferritin and Type-2 Diabetes Mellitus. JK Science. 2008; 10(4):170-74.

28. Mateo-Gallego R, Calmarza P, Jarauta E, Burillo E, Cenarro A, Civeira F. Serum ferritin is a major determinant of lipid phenotype in familial combined hyperlipidemia and familial hypertriglyceridemia. Metabolism. 2010 Feb 1; 59(2):154-8.

29. Shim YS, Kang MJ, Oh YJ, Baek JW, Yang S, Hwang IT. Association of serum ferritin with insulin resistance, abdominal obesity, and metabolic syndrome in Korean adolescent and adults: The Korean National Health and Nutrition Examination Survey, 2008 to 2011. Medicine. 2017 Feb; 96(8).

\section{The Authors:}

Dr. Rafiq Ahmad Siddiqui

Demonstrator, Department of Biochemistry, Services Institute of Medical Sciences, Lahore
Prof. Tahira Naseem

HOD Biochemistry \& Chemical Pathology, Shaikh Zayed Medical Complex, Lahore

Dr. Farhana Mukhtar

Assistant Professor,

Department of Biochemistry \& Chemical Pathology, Shaikh Zayed Medical Complex, Lahore

Dr. Ambreen Farrukh

Assistant Professor,

Department of Chemical Pathology

Abwa Medical College, Faisalabad

Dr. Sadia Liaqat

Women Medical Officer,

Gynae Hospital Union Council 37,

New Karol, Lahore

\section{Corresponding Author:}

Dr. Rafiq Ahmad Siddiqui

Demonstrator,

Department of Biochemistry,

Services Institute of Medical Sciences, Lahore

Email: rafiqsiddiqui66@gmail.com 